УДК 37.011.31-051

10.17213/2075-2067-2020-5-98-105

\title{
АКТИВИЗМ УЧИТЕЛЕЙ В РОССИЙСКИХ ЛОКАЛЬНОСТЯХ: СОВРЕМЕННЫЕ ТЕНДЕНЦИИ
}

\author{
(C) 2020 г. Н. В. Левченко \\ Институт социологии Федерального научно-исследовательского \\ социологического центра РАН, г. Москва, Россия
}

Цель статьи. В статье анализируется отношение учителей к своей профессиональной деятельности в российской провинции.

Методы исследования. Данные получены в ходе полевых исследований в 2013-2015 г2. и в 2019 г. в пятнадияати регионах РФ, осуществлявшихся методом глубинных интервью и фокус-групп.

Результаты исследования. Выявлена гражданская активность учителей и директоров школ и её значимая роль в сочиокультурном развитии местных сообществ. Исследование показало, что ситуация в районных цуентрах постепенно меняется, возникла тенденция снижения активизма работников образования. Учителя чаще предпочитают следовать инструкциям, не пытаются выйти за рамки, как это было ранее. Основными факторами изменения позиции учителей стали реформирование системы образования и глобальные трансформащии в подходе к воспитанию детей, проявляющиеся в форме давления на учителей со стороны родителей школьников. Сделан вывод о том, что снижение активизма педагогов ведёт к ухудшению сочиокультурной ситуачии в малых городах и посёлках, а также к снижению качества выпускников местных школ.

Ключевые слова: локальность; активизм; школа; учебный прочесс; преподавательская деятельность.

\section{TEACHER ACTIVISM IN RUSSIAN LOCALITIES: CURRENT TRENDS}

\author{
(C) $2020 \quad$ N. V. Levchenko
Institute of Socilogy of the Federal Research Sociological Center of the Russian Academy of Sciences, Moscow, Russia

The purpose of the research. The article analyzes the attitude of teachers to their professional activities in the Russian province.

The research methodology. The data were obtained in the course of field research in 20132015 and 2019 in fifteen regions of the Russian Federation, carried out by the method of in-depth interviews and focus groups.

Research result. The article reveals the civic activity of teachers and school principals and its significant role in the socio-cultural development of local communities. The study showed that the situation in district centers is gradually changing, and there is a tendency to reduce the activism of education workers. Teachers often prefer to follow instructions, not try to go beyond the limits, as it was previously. The main factors in changing the position of teachers were the reform of the education system and global changes in the approach to child rearing, which are manifested in the 
form of pressure on teachers from parents of schoolchildren. It is concluded that the decrease in the activism of teachers leads to a deterioration of the socio-cultural situation in small towns and villages, as well as to a decrease in the quality of graduates of local schools.

Key words: locality; activism; school; educational process; teaching activity.

Введение. В Российской глубинке школа традиционно, начиная со школы земской, играла важную роль в жизнедеятельности местного сообщества, в немалой степени способствовала его развитию, а также сохранению его социокультурной среды в сложные исторические периоды, включая постперестроечный $[3,1]$. Под воздействием школьного образования складывается жизненный старт молодежи, её образовательные и профессиональные пути, которые предварительно формируют работника и гражданина [7]. В последнее время система школьного российского образования трансформируется, внедрение нововведений меняют саму суть обучения [4], образовательный процесс формализуется и технологизируется. В связи с этим на местном уровне решающее значение приобретает позиция педагогического сообщества. С социологической точки зрения, основным оказывается вопрос, приняли ли преподаватели нововведения, изменилось ли их место в жизни российских локальностей?

Эмпирическую базу исследования составили проведённые коллективом глубинные интервью и фокус-группы в ходе выполнения проектов Сектора изучения социокультурного развития регионов России. Исследование проводилось в 2 этапа: первый проходил в 2013-2015 гг., второй — в 2019 г.

Для исследований в 2013-2015 гг. были выбраны следующие регионы РФ: Архангельская, Ивановская, Калужская, Курская, Нижегородская, Орловская, Псковская, Смоленская, Свердловская и Тамбовская области, Республика Крым, в 2019 г:: Астраханская, Калужская и Курская области, Республика Карелия и Алтайский край. В общей сложности было собрано 141 глубинное интервью и 31 фокус-группа. Значительная часть результатов полевых исследований 2013-2015 г. опубликована, и первый раздел данной статьи основан на вторичном анализе этих публикаций.

На основании собранных данных на интернет-ресурсах и проведённых глубинных интервью с представителями региональной власти в каждом из регионов были выбраны (в большинстве случаев) два районных центра для проведения исследования. Как правило, один район выбирался из числа наиболее благополучных и один малоресурсный район.

В связи с тем, что предметом исследования является, прежде всего, профессиональный и социальный активизм педагогов, глубинные интервью в каждом районном центре были проведены с директорами и учителями местных школ. Кроме того, были опрошены и сотрудники библиотек, музеев и Домов культуры, работники учреждений дополнительного образования, так как на локальном уровне они практически всегда взаимодействуют с учителями в образовательном процессе и активно участвуют в жизни местного сообщества.

Для выявления активистов среди представителей выбранных профессиональных групп в качестве респондентов были опрошены местные жители, в том числе их дети и представители районной администрации (особенно в тех случаях, когда их дети проживали и обучались в данном районном центре). Именно они могут рассказать о педагогах, актуализирующих свои ценности в гражданской активности и в профессиональной деятельности.

В исследованиях И.А. Халий и О.А. Аксеновой, осуществлявшихся в 1990-е и 2000-е годы, было обнаружено, что педагогическое сообщество в учебных заведениях районного центра проявляют активизм профессиональный (дают знания, сверх того, что требуется, занимаются воспитанием учеников, работают с неблагополучными семьями) и гражданский (например, борются с алкоголизмом и наркоманией, участвуют в организации культурной жизни локальности). О.В. Аксенова обозначила данный характер профессионального действия как акторский, основанный не только на компетенциях, но и на ценностях. В данном случае это тер- 
мин, обозначающий определённый характер социального действия (свободного, основанного на ценностях). Определение акторского действия основано на концепте актора (действующего субъекта) А. Турена [6]. Его противоположностью является формализованное, алгоритмизированное действие, субъект которого не может выйти за рамки заданной программы [1]. По её мнению, акторское действие до сих пор сохраняется в российской провинции [2].

Основные направления развития активизма учителей. Анализ интервью показал, что вопреки закону «Об образовании» ${ }^{1}$ во всех исследуемых районах воспитание детей оставалось в период 2013-2015 гг. важной задачей образования в малых городах и сёлах. В ходе исследования был выявлен индивидуальный подход к каждому ученику, сохранение тесных связей между учеником и учителем, традиционных для провинциальной русской школы.

Сопротивление инновациям было выявлено и в процессе обучения, так, многие преподаватели готовили учеников к ЕГЭ и ГИА во внеурочное время, отказавшись от их «натаскивания» на сдачу данных экзаменов в учебное время. У районных учителей была установка на то, чтобы все их ученики обязательно поступили в вузы и продолжили образование, ради достижения этой цели они готовы безвозмездно заниматься с учениками, давать им знания сверх программы. Инновации, транслируемые из центра, адаптировались директорами и учителями учебными заведениями. Как правило, для школ характерны следующие сюжеты: нововведения вынужденно поддерживались преподавательским сообществом, например, процесс оптимизации на районном уровне подразумевает сокращение числа образовательных учреждений или присоединение малоресурсной школы к более крупной. Другие нововведения трансформировались и адаптировались директорами и преподавателями, так как были неприемлемы для них и для местного сообщества. Например, минимизация функции воспитания для большинства локальностей губительна. Школа в селе стремилась противостоять девиантному поведению молодёжи, которое было реальной угрозой, в том числе и учителям. Определенные инновации охотно принимаются населением и полностью поддерживаются учительскими сообществами, к их числу в основном относится техническое оснащение школ.

В районах осуществлялась серьёзная работа по внешкольному образованию детей, работали творческие, музыкальные и спортивные учреждения. Как правило, в школах искусств занимаются в среднем по 200 человек. Большинство учеников ходят на занятия по дополнительному образованию, как в свою школу, так и в Дома культуры или в специализированные учреждения. В основном преподаватели дополнительного образования ведут свою деятельность для повышения культурного уровня учащихся, прививают интерес к занятиям спортом и к здоровому образу жизни. Эти цели распространялись на всех, особенно на детей из неблагополучных семей и детей с отклонениями. Интервью также показали, что поддержание культурных традиций держится только на инициативе и энтузиазме учителей дополнительного образования и деятелей культурно-досуговых учреждений, которые остаются одними из главных носителей российской культуры в районных центрах регионов России [5].

Активная гражданская позиция учителей влияет и на результаты школьной преподавательской деятельности. Выпускники практически всех районных школ (нередко около $100 \%$ ) поступали в вузы и ссузы районных и областных центов, в ведущие вузы Москвы и Санкт-Петербурга.

Таким образом, в 2013-2015 гг. было обнаружено, что, видимо, благодаря сложившимся традициям в провинции российские учителя пока не были готовы принимать нововведения, не соответствующие их устоявшимся представлениям о преподавании. Кроме того, российские школы пока не перенимают навязываемые европейские стандарты, даже несмотря на то, что некоторые исследуемые районы имеют тесные контакты со странами Евросоюза: в России до сих пор

1 Федеральный закон РФ «Об образовании в Российской Федерации» №273-Ф3, 2013 // Кодексы и законы РФ. 2013. Режим доступа: http://www.zakonrf.info/zakon-ob-obrazovanii-v-rf/. 
редко где можно увидеть школьные учреждения, которые были бы ориентированы на уровень образования, доступный «отстающим». Во время полевых исследований был обнаружен только один лицей, выполняющий такую установку. В основном учителя продолжают практику обеспечения высокого уровня образования для всех.

Тенденция снижения активизма учителей. В 2019 г. было выявлено заметное снижение активизма учителей, что обусловлено целым рядом факторов, основными из которых являются последствия реформ в образовании и изменение установок учеников и их родителей.

Последствия образовательных реформ на местном уровне. Тестовая система проверки знаний (ЕГЭ и ОГЭ (ГИА)) является одним из факторов формализации образовательного процесса. Учителя долго сопротивлялись её влиянию, считая необходимым (по их словам) научить ребёнка думать. Однако подготовка к ЕГЭ стала приоритетной, в ней заинтересованы и родители учеников, так как от результатов единого экзамена зависит поступление их ребёнка в вуз или ссуз.

Формализации обучения способствует растущий бюрократизм, необходимость его ограничения уже общепризнана. Учителям по-прежнему приходится большую часть рабочего времени тратить на ведение и заполнение отчетов и документации. В результате у педагогов практически нет возможности уделять внимание своему предмету и ученикам, нет времени делать что-то сверх программы.

Взаимодействие учителей и родителей школьников. Как показало наше исследование, среди родителей все больше распространяется идея защиты прав ребенка в школе, которая чаще всего принимает гипертрофированную форму. Родители, которые четко приняли установку, что ребенок - личность и имеет право на отстаивание своих интересов, активно начинают «борьбу» против учителей. Некоторые из них полагают, что учителя слишком жестко обращаются с детьми, хотя это проявляется в большинстве случаев в том, что учителя продолжают воспитывать учеников. В ряде случаев достаточно одного-двух родителей для того, чтобы убедить остальных, что детей нельзя заставлять, что ребенок должен сам захотеть учиться и т.п. В основном, именно давление со стороны родителей приводит к изменению позиции учителей. Это подтверждают сотрудники учреждений, которым по роду деятельности приходится взаимодействовать с детьми и подростками: «Всё зависит от классного руководителя, если он заинтересован успеваемостью класса, отдельного ребёнка, то занимаются. Но в иелом школьы уходят от воспитания» (фокус-группа с сотрудниками центра занятости, Суоярви).

В результате, даже те учителя, которые не хотели бы следовать данным условиям, вынуждены либо уходить из школы, либо принимать новые «правила игры»: «Я раньше работала в школе, не выдержала. Дети стали вести себя ужасно, если сделаешь им выговор, то придут родители, и ты еще останешься виноватылм» (фокус-группа с представителями администрации, Обнинск).

Однако было выявлено, что далеко не во всех районных центрах наблюдается данная ситуация. Этому может способствовать жесткая позиция директора и преподавательского состава школы: «У нас была пара родительнии, которые возмущались, они хотели убедить и других родителей, что детям надо давать больше свободы, чтобы учителя их не заставляли и не воспитывали. Но мы им объяснили, что это неправильная позиция, что последствия будут плачевными» (из интервью с учителем школы, Алтайский край).

Потеря значимости учителей для икольников. Учитель уже потерял ту значимость для учеников, которая была раньше. Вопервых, родители, защищая права своих детей в школе, способствуют тому, что профессиональный компонент авторитета учителя перестает быть безусловным для школьников. Вовторых, этому способствует повсеместное неконтролируемое использование школьниками Интернета, где одним из самых популярных источников знаний у подрастающего поколения становятся страницы блогеров.

Теперь учитель перестал быть уникальным источником знаний. У школьников появилась иллюзия, что они сами могут найти необходимую информацию. По их мнению, учителя «отстали» от современных трендов и не могут дать те знания, которые им действительно пригодятся в жизни. 
Получение знаний в Интернете имеет ряд негативных последствий.

1) Как правило, блогеры не несут ответственности за предоставление своего материала, не умея отбирать и фильтровать материал, а дети доверяют информации, полученной от блогера.

2) Школьники и студенты начинают считать, что нет необходимости получать фундаментальные знания и даже, возможно, профессию, так как можно вести блог и получать за это достойную оплату. В результате в будущем мы можем получить общество псевдопрофессионалов: «Мой сын сказал, что он уже умеет читать и писать, ездить на лошади, а потому ему пора бросать школу, вести блог, а летом обслужсивать туристов» (из интервью с учителем сельской школы, Республика Алтай).

3) В связи с тем, что дети склонны к поиску образцов для подражания, они выбирают авторитетных (в их среде) личностей, сейчас, как правило, это блогеры, в числе наиболее популярных - Юрий Дудь. По мнению наших респондентов, именно он поднимает острые вопросы, интересные молодым людям.

Активизм учителя зависит не только от трансформаций самого образовательного процесса. Он зависит также и от позиции учеников, от их жизненных целей и ценностей. Изменение последних можно проследить по интервью со студентами местных учреждений среднего специального образования, недавних школьников. Они всё чаще связываются с материальным успехом: «начать зарабатывать», «в жсизни подняться», «купить машину, купить дом» (из фокус-групп со студентами техникумов). Молодые люди ориентируются на жизнь в большом городе, а некоторые - на эмиграцию за границу.

Труд уже перестает быть ценностью для подрастающего поколения, преобладающей ценностью становится оплата этого труда. Ситуация усугубляется и массовой потерей интереса к обучению. В результате ни учителя, ни родители не объясняют детям, зачем нужно получать фундаментальные знания.

Коммерциализация образования. Исследования 2019 г. показали, что теперь все чаще занятия становятся платными (репетиторство). Платными становятся кружки и секции при школах, куда раньше мог свободно прий- ти любой школьник, вне зависимости от доходов его родителей.

Примерно такая же ситуация сложилась и в сфере дополнительного образования, в клубах и Домах культуры. Но проблема не только в платности. Сами учащиеся теряют интерес к ремесленным и творческим занятиям, им стало сложнее там обучаться (теряется навык преодоления трудностей). Например, в техникуме искусств, где в 2015 г. директор был полон энтузиазма и с удовольствием рассказывал о занятиях, в 2019 г. он был уже поникшим и потерянным: "Дети стали чаще уходить после первых лет обучения, им стало сложно воспринимать и усваивать знания, учиться. Трудно, поэтому уходят» (директор техникума искусств, Курская область).

Ориентация учеников на переезд в крупный город. Проблема заключается в том, что дети из районов стремятся уехать для продолжения учебы в более развитые региональные центры и дальше, причем речь идет не о желании жить и работать в Москве, Санкт-Петербурге или за границей, а преимущественно в других регионах РФ. Остаются ребята, которые учились слабо, остаются жить и продолжают обучение в своих же районах: «Сегодня в педагогический колледж приходят только троечники, т.е. те, у кого знаний практически нет. Их уже бесполезно обучать чему бы то ни было. Я стараюсь просто объяснить им, как быть нормальнымм человеком» (из интервью с преподавателем колледжа, Старица, Тверская область).

Такая ситуация может существенно изменить социокультурную среду локальностей, которая формировалась и воспроизводилась, в том числе педагогами-акторами.

Активизм ещё жюив. Активизм еще не полностью ушел из общеобразовательных школ и организаций по дополнительному образованию в российской провинции. В нашем исследовании мы по-прежнему встречали случаи его проявления: «B приоритете стоит занятость детей, родители работают, и нужно максимально занять детей, чтобы у них были дела. Занятость детей составляет $80 \%$, с каждым годом увеличивается количество детей, мы сами занимаем детей, поэтому меньше времени на хулиганство» (фокус-группа с представителями администрации, Астраханская область, Лиман). 
«У нас есть учительнииа дзюдо, она набрала мальчиков-беспризорников. Все ребята поменялись, эта учительница стала примером для них, дети ездят на конкурсы, на соревнования и вылгрывают» (фокус-группа с представителями администрации, Астраханская область, Лиман).

«Mb занимаемся просвещением и воспитанием, проводим опросы, викторины. $\mathrm{Mbl}$ делаем многое, чтобы ребенку было интересно. У нас есть сотрудница, которая этому отдает все свое свободное время! И даем знания, которые в школе не успевают дать! Но никто этого не видит! Mы проводим бесеdbl c детьми» (фокус-группа с сотрудниками библиотеки, Калужская область, Обнинск).

Мы по-прежнему часто слышали то, что все держится на энтузиастах, и если уйдут они, то все окончательно рухнет: «Во всём нужен энтузиазм, прийти не просто посидеть. Нам нужны люди, которые горят своим делом» (фокус-группа с представителями администрации, Астраханская область, Лиман).

В свою очередь многие школьники пока еще продолжают быть нацеленными на получение образования. В ходе исследований как в 2013-2015 гг., так и в 2019 г. было выявлено, что практически все поступают в вузы и ссузы районных и областных центров, в ведущие вузы страны.

Выводы. Исследования обнаружили тенденцию сокращения гражданской активности учителей, которая в 2019 г. обозначилась вполне отчётливо. Большую роль в её появлении играет формализация образования: строгое следование установленной норме и заданному алгоритму действия неизбежно минимизирует проявления активизма, основанного в значительной степени на ценностях.

Не менее важными факторами снижения активизма является растущая коммерциализация образования, новые установки учеников и их родителей, ведущие в числе прочего к снижению значимости роли учителя в жизни учеников. Учителя школ уже не могут идти наперекор сложившимся тенденциям, они начинают приспосабливаться к ним, предоставляя только образовательные услуги. В противном случае им либо приходится уходить из школы (воспитание школьников зачастую приводит к конфликтам с их роди- телями), либо бороться с системой, но на это уже нет ни сил, ни желания, а главное - учителя перестают чувствовать отдачу от учеников, поддержку со стороны родителей и местного сообщества в целом. Учитель-актор перестаёт воспитывать учащихся и, следовательно, перестаёт быть актором.

Теперь районные учителя не всегда готовы безвозмездно заниматься с учениками, индивидуальный подход к каждому ученику сменяется механическим выполнением профессиональных обязанностей.

В результате, если в предыдущие годы школы в российской провинции были не только образовательными, но и культурными центрами, поддерживали в малых городах и в посёлках определенный социокультурный уровень, то сейчас этот уровень явно падает. Локальности могут оказаться в бедственном положении и потому, что там не первый год остаются жить и продолжать обучение те, кто в школе учился слабо и у кого в большинстве случаев практически неблагополучные семьи.

Пока всё перечисленное - лишь тенденция, но следствием её усиления может стать усиление деградации локальностей. Разумеется, деградация обусловлена в первую очередь экономическими причинами, но в предыдущие десятилетия деятельность местных акторов, среди которых были учителя и директора школ, позволяла сохранять достаточно высокий уровень социокультурного развития сообщества в условиях экономического кризиса и стагнации. Более того, подготовку выпускников многих районных школ высоко оценивали преподаватели региональных вузов. Если современную тенденцию снижения активизма не изменить в ближайшее время, то будет снижаться социокультурный потенциал страны в целом, который пока ещё складывается из множества локальностей.

\section{Литература}

1. Аксенова О.В. Парадигма социального действия: профессионалы в российской модернизации: монография. - М.: Институт социологии РАН, 2016. - 304 c.

2. Аксенова О.В. Модели управления в России и на Западе: риски и перспективы развития // Россия реформирующаяся: еже- 
годник: вып. 16 / Отв. ред. М.К. Горшков. М.: Новый Хронограф, 2018. - С. 348-372.

3. Акторская парадигма управления в эпоху перемен: адаптация или противодействие // Россия реформирующаяся: Ежегодник [сборник научных статей] / Отв. ред. М.К. Горшков; Институт социологии РАН. - Москва: Новый хронограф. - 2016. - Вып. 14. C. 336-357.

4. Байрамова Ж. М. Интеграция образования и науки как движущая сила модернизации экономики России // Известия Пензенского государственного педагогического университета им. В.Г. Белинского. - 2011. №4. - С. 174-180.

5. Левченко Н.В. Модернизация системы образования: отношение учителей к возникающим рискам // Гуманитарные и социально-политические проблемы модернизации Кавказа. Сборник научных статей VI-й Международной конференции / Отв. ред. Сампиев И.М. - Назрань: ООО «КЕП», 2018. С. 316-324.

6. Турен А. Возвращение человека действующего. Очерк социологии. - М.: Научный мир, 1998. - 206 с.

7. Чередниченко Г.А. Российская молодежь в системе образования: от уровня к уровню // Вопросы образования. — 2016. №3. - С. 152-182.

\section{References}

1. Aksenova O. V. Paradigma social'nogo dejstvija: professionaly v rossijskoj modernizacii: monografija [Paradigm of social action: professionals in Russian modernization]. - Moscow: Institut sociologii RAN, 2016. - 304 p.

2. Aksenova O.V. Modeli upravlenija $\mathrm{v}$ Rossii i na Zapade: riski i perspektivy razvitija [Management Models in Russia and the West: risks and development prospects] // Rossija reformirujushhajasja: ezhegodnik: vyp. 16 [Russia reforming: Yearbook: issue 16] / In M.K. Gorshkov (eds.). - Moscow: Novyj Hronograf, 2018. - Pp. 348-372.

3. Aktorskaja paradigma upravlenija $\mathrm{v}$ jepohu peremen: adaptacija ili protivodejstvie [The actor paradigm of management in an era of change: adaptation or opposition] // Rossija reformirujushhajasja: Ezhegodnik [sbornik nauchnyh statej] [Russia is reforming: Yearbook (collection of scientific articles)] / In M.K. Gorshkov (eds.); Institut sociologii RAN. - Moscow: Novyj hronograf. — 2016. — Issue 14. Pp.336-357.

4. Bajramova Zh. M. Integracija obrazovanija i nauki kak dvizhushhaja sila modernizacii jekonomiki Rossii [Integration of education and science as a driving force for the modernization of the Russian economy] // Izvestija Penzenskogo gosudarstvennogo pedagogicheskogo universiteta im. V.G. Belinskogo [Izvestiya Penza state pedagogical University named after V.G. Belinsky]. — 2011. — №4. - Pp. 174-180.

5. Levchenko N.V. Modernizacija sistemy obrazovanija: otnoshenie uchitelej $\mathrm{k}$ voznikajushhim riskam [Modernization of the education system: teachers ' attitude to emerging risks] // Gumanitarnye i social'no-politicheskie problemy modernizacii Kavkaza. Sbornik nauchnyh statej VI-oj Mezhdunarodnoj konferencii [Humanitarian and socio-political problems of modernization of the Caucasus. Collection of scientific articles of the VI-th International conference] / In Sampiev I. M. (eds.) - Nazran': OOO «KEP», 2018. - Pp. 316-324.

6. Turen A. Vozvrashhenie cheloveka dejstvujushhego. Ocherk sociologii [Return of the active person. Essay of sociology]. - Moscow: Nauchnyj mir, 1998. — 206 p.

7. Cherednichenko G.A. Rossijskaja molodezh' v sisteme obrazovanija: ot urovnja k urovn$\mathrm{ju}$ [Russian youth in the education system: from level to level] // Voprosy obrazovanija [The issue of education]. — 2016. — №3. - Pp. 152-182. 


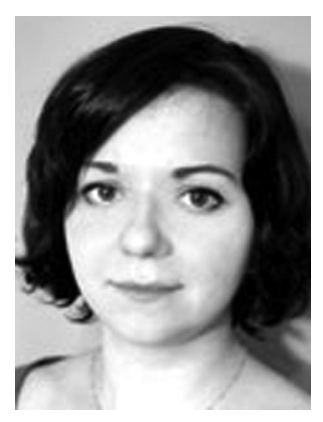

Левченко Наталья Валерьевна - научный сотрудник Института социологии Федерального научно-исследовательского социологического центра РАН.

Levchenko Natalia Valeryevna - Scientific Researcher, Institute of Sociology of the Federal Research Sociological Center of the Russian Academy of Sciences.

117218 , г. Москва, ул. Кржижановского, 24/35

24/35 Krzhizhanovskogo st., 117218, Moscow, Russia

E-mail: natalya_levchenk@mail.ru 